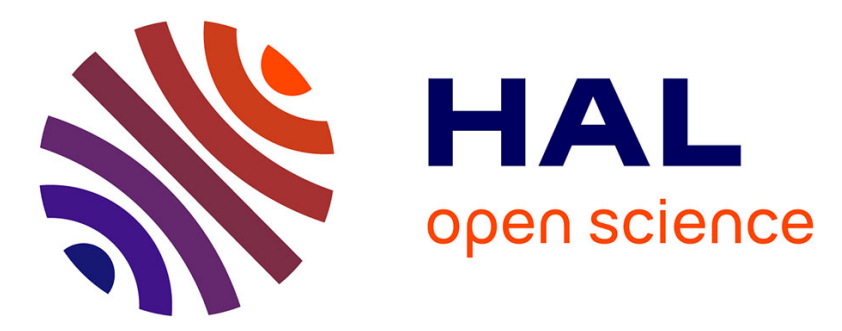

\title{
Helping Students Understand Courses through Written Syntheses An LSA-based Online Advisor
}

Emmanuelle Villiot Leclercq, Sonia Mandin, Philippe Dessus, Virginie Zampa

\section{To cite this version:}

Emmanuelle Villiot Leclercq, Sonia Mandin, Philippe Dessus, Virginie Zampa. Helping Students Understand Courses through Written Syntheses An LSA-based Online Advisor. 10th IEEE International Conference on Advanced Learning Technologies, 2010, Sousse, Tunisia. pp.341-343, 10.1109/ICALT.2010.96 . hal-01820372

\section{HAL Id: hal-01820372 \\ https://hal.science/hal-01820372}

Submitted on 21 Jun 2018

HAL is a multi-disciplinary open access archive for the deposit and dissemination of scientific research documents, whether they are published or not. The documents may come from teaching and research institutions in France or abroad, or from public or private research centers.
L'archive ouverte pluridisciplinaire HAL, est destinée au dépôt et à la diffusion de documents scientifiques de niveau recherche, publiés ou non, émanant des établissements d'enseignement et de recherche français ou étrangers, des laboratoires publics ou privés. 


\title{
Helping Students Understand Courses through Written Syntheses
}

\author{
An LSA-based Online Advisor
}

\author{
Emmanuelle Villiot-Leclercq \\ IUFM de Grenoble \\ Grenoble University \\ Grenoble, France \\ Emmanuelle.Villiot- \\ Leclercq@ujf-grenoble.fr
}

\author{
Sonia Mandin, Philippe Dessus \\ Lab. sciences de l'éducation \\ Grenoble University, France \\ Grenoble, France \\ Sonia.Mandin@msh-alpes.fr \\ Philippe.Dessus@upmf- \\ grenoble.fr
}

\author{
Virginie Zampa \\ LIDILEM \\ Grenoble University, France \\ Grenoble, France \\ Virginie.Zampa@gmail.com
}

\begin{abstract}
In a life-long learning context, learners have to perform a lot of writing-based activities, like document analysis, that are seldom assessed by teachers or tutors because this assessment is time-consuming. We introduce a service, Pensum, integrated in a PLE that helps students to understand a course content through writing a synthesis, as well as teachers and tutors to manage this activity. Based on natural language processing techniques, Pensum proposes just-in-time and reflexive feedback on a complex writing task.
\end{abstract}

Key words: Automated feedback; written synthesis; Latent Semantic Analysis; PLE

\section{INTRODUCTION}

In numerous educational contexts, learners produce textual reports (e.g., summaries, essays, syntheses) about the notions they learn, and feedback is offered about their results. They encounter some problems: the long waiting time for feedback (stagnating them in the writing process); the limited feedback opportunities do not stimulate explorative approaches, but force them to hand in mainly completed versions. Moreover, students find it difficult to self-assess their work during writing and to perceive possible misunderstandings. Tutors who guide this activity also encounter problems. They are often not experts on the content taught, they provide support to students that often fits loosely with the instructional activities; they have also trouble to issue a just-in-time feedback during the different activities as discussion or writing; finally, they have to manage successive versions of students' summaries, whose discrepancies are often difficult to grasp.

In this article, we present Pensum, an on-line document advisor, which aims at helping learners to improve their synthesis writing activity and at instrumenting tutors' assessment. Pensum is integrated in a Personal Learning Environment (PLE) and analyses how well learners understand course texts as shown by their textual productions; it provides frequent justin-time feedback based on LSA (Latent Semantic Analysis) [1] on the ongoing writing activities (relevance of written sentences, inter-sentence coherence of the synthesis, overlapping between course text and synthesis sentences). We argue that Pensum improves student's understanding of course texts and gives teachers and tutors more opportunities to guide students' higher-level processes in a lifelong learning context.

We first present the main characteristics of automated feedback for supporting the task of writing syntheses, then we describe the architecture of Pensum.

\section{FEEDBACK FOR SUPPORTING DOCUMENT SYNTHESIS TASK IN A PLE}

In academic tasks like document synthesis, students are asked to demonstrate their understanding of source texts they read-proposed by their teacher in courses-by composing a new abridged text [2]. Discourse synthesis is a cognitively demanding activity requiring students to transform knowledge [3] rather than simply reproduce information from a single source. It entails to write a new text and to construct new meaning by using three key operations: selecting information according to the writer's goals, connecting this information to achieve a cohesive text, and organizing it according to the intended goals $[2,4]$. Synthesis writing is a complex task which must be supported by teachers and tutors. How to deliver appropriate feedback for guiding this process and improving learning. What are the criteria of an effective feedback? Several ways to enhance the feedback effectiveness have been determined [5]:

- feedback must focus students attention on their progress in mastering educational tasks;

- feedback should take place while it is clearly relevant during the learning process (e.g., being just-in-time);

- feedback should be specific and related to student's needs and learning tasks.

The literature underlines the need to promote ways to deliver formative feedback on writing-based tasks [6] and to mix verification feedback (indicating if the answer is correct or not) and elaboration feedback (helping learners find the correct answer with a set of relevant cues) [7].

\section{PENSUM : AN APPLICATION FOR PROVIDING FEEDBACK ON DOCUMENT SYNTHESIS TASKS}

The aim of Pensum is to give learners assessments on their written productions, and thus to make the teachers' or tutors' assessment process 
smoother. For that, Pensum proposes several kinds of feedback that help students understand both the texts they read and the pieces of texts they write as a synthesis. The feedback allows students to stay focused on the information they need to understand in the source texts. Moreover, the feedback directly indicates the parts of source texts lacking in the synthesis and those of the synthesis to revise. We describe now a learning scenario inserting Pensum in an academic context.

\section{A. Learning Scenario}

Ulysses is a second-year master student in computer science, attending a course on educational applications remotely. He can launch Pensum, a web service (see Figure 1). He selects a course domain he wants to revise, for instance, a course on Natural Language Processing (NLP).

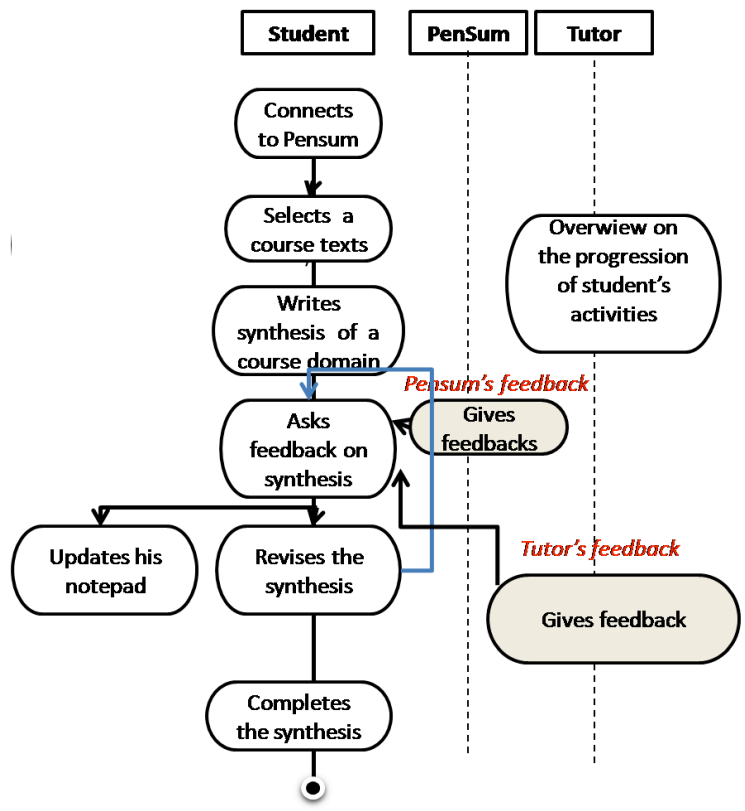

Figure 1. The role of actors using Pensum in a PLE.

He starts to write a synthesis about the most important ideas of the understood course. Whenever Ulysses is uncertain about whether he grasps the most important notions of a text, he asks support from Pensum. The system gives Ulysses a feedback on his written synthesis, e.g., relevance of the sentences or inter-sentence coherence of the synthesis. At any moment, the tutor in charge of Ulysses' supervision can connect to Pensum, can see what Ulysses has already written and can read the feedback given by the system. He can also give some feedback in the forum to help Ulysses.

Ulysses is in control of his own learning process, he requests feedback whenever he wants and can update his notepad according to the main points he has understood and can go further in the writing of the same synthesis or one related to another topic.

\section{B. Types of Feedback Integrated in Pensum}

In this first version of Pensum, we are just focusing on the immediate feedback based on LSAbased computational cognitive models. LSA has been presented to be useful for modeling human semantic memory [1]. LSA represents the words of a huge corpus in a high-dimensional space, from the idea that the meaning of words depends on contexts where they occur. In this space, each word is represented as a vector and groups of words (e.g., sentences, paragraphs, or texts) as a sum of word vectors. Then, the semantic proximity between two textual elements is defined by the vector distance (e.g., the cosine), which LSA provides.

This model can be used to simulate the understanding of texts and to analyze summaries of short explanatory texts. For example LSA can be used to measure the coherence of texts and hence, learning, since the understanding of a given text depends on its coherence [8]. This capability of LSA has also been used in other systems like Apex [9], which uses the same measure of coherence to give feedback; or Summary Street, which sends feedback about the relevance and the redundancy of sentences $[10,11]$.

In Pensum, several types of feedback have been integrated according to the activity flow depicted in Figure 1, and to the interaction between the tasks, the resources and actors: first, an immediate and computer-based feedback, as many times as necessary. This LSA-based feedback is obtained by comparing the written synthesis with the courses. Second, a delayed feedback, given by teachers and tutors via the system. To help tutors or teachers deliver adequate feedback on student's syntheses, a list of recurrent understanding and writing problems based on Thibaudeau's framework [12] is provided. This categorization of problems is built according to a design patterns approach [13]. Figure 2 displays the main feedback window: the uppermost text field contains the course text and the above table is a comprehensive list of the sentences of the synthesis regarding their relevance and coherence.

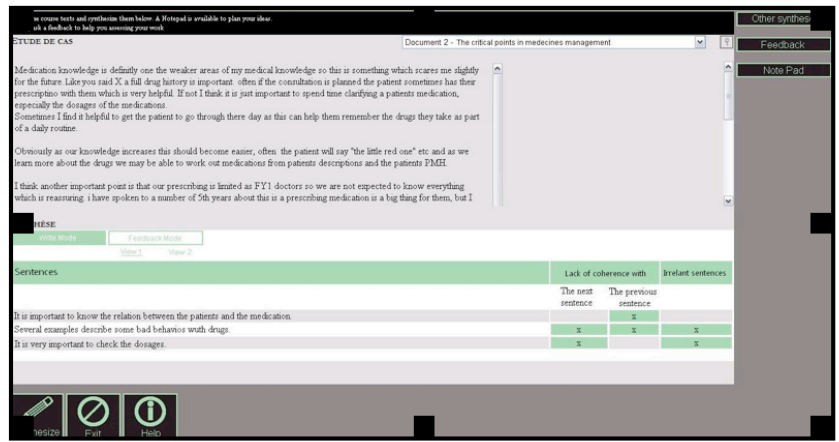

Figure 2. A screendump of Pensum (assessment window).

Moreover, several types of immediate feedback have been implemented as follows. The coherence of the synthesis (LSA compares the semantic 
proximities between nearby sentences), the relevance of its sentences (LSA compares each sentence of the text to each sentences of the courses text) and its completeness (LSA compares the semantic proximities between each course topic and the synthesis).

The coherence assessment [8] model can check if two given sentences in the same paragraph are coherent, provided that two consecutive sentences are coherent if their semantic proximity is above a threshold. The relevance assessment model reused the Summary Street's model [10, 11], provided that a relevant sentence is a sentence similar to at least one sentence of the source texts. Regarding the completeness assessment model (does the synthesis cover all the course text topics?), two alternate models have been proposed. First, we computed a measure with respect to course text topics (a topic is a keyword representing the gist of a text), i.e., the semantic proximity between the synthesis and the block of sentences linked to the topic in the course texts. A sentence of a course text is in this block if the semantic proximity between the sentence and the topic is high enough. If the semantic proximity between the block of sentences and the topic is high then the topic is covered; if not, the student is prompted that the topic is not covered. Second, we computed a measure with regard to the semantic relation between the sentences of the course text and the sentences of synthesis (a sentence of the course text is indicated as not summarized in the synthesis if there is not enough semantic proximity between this sentence and each sentence of the synthesis).

These types of feedback have been tested in several experiments $[4,11,14]$ but the correlations between the model results and the human judges answers are were not sufficiently high. The lack of validity of computer feedback led us to propose it as an indicative feedback likely wrong, instead as a corrective feedback. So, we expect the students should use this feedback to stay focused on some important characteristics of their syntheses, instead of being fully certain that the feedback is valid.

\section{CONCLUSION}

In lifelong learning contexts students have irregular contacts with their tutors and teachers, and get few assessments on their understanding. In this article, we bring to light the interest of the synthesis production task supported by an automated feedback based on LSA. We introduced Pensum, a service aimed at helping students in their learning activity through synthesis writing. The service integrated to a PLE provides students with just-in-time feedback on this task. It helps students make explicit what knowledge is built and by which processes and strategies.

We are going on with an implementation and a validation of Pensum in educational settings. Both quantitative and qualitative analyses will be undertaken. We aim at collecting data on students' and tutors' opinion on the service, its usability and learning aspects. In addition we will collect data on students' cognitive workload and we will track students' to analyze their learning and meta-cognitive strategies.

\section{ACKNOWLEDGMENT}

This work was partly supported by the 7th Framework Programme (Theme FP7-ICT-2007-14.1) of the European Community (LTFLL-STREP Project, Grant no 212578).

\section{REFERENCES}

[1] T. K. Landauer and S. T. Dumais, "A solution to Plato's problem: the Latent Semantic Analysis theory of acquisition, induction and representation of knowledge," Psychological Review, vol. 104, pp. 211-240, 1997.

[2] N. Spivey, The constructivist metaphor: Reading, writing, and the making of meaning. New York: Academic Press, 1997.

[3] C. Bereiter and M. Scardamalia, The psychology of written composition. Illsdale: Erlbaum, 1987.

[4] R. Segev-Miller, "Writing from sources: the effect of explicit instruction on college students' processes and products," L1-Educational Studies in Language and Literature, vol. 4, pp. 5-33, 2004.

[5] T. J. Crooks, "The impact of classroom evaluation practices on students," Review of Educational Research, vol. 58, pp. 438-481, 1988.

[6] S. Lindblom-Ylänne, H. Pihlajamäki, and T. Kotkas, "Self-, peer- and teacher-assessment of student essays " Active Learning in Higher Education, vol. 7, pp. 51-62, 2006.

[7] R. W. Kulhavy and W. Stock, "Feedback in written instruction: The place of response certitude," Educational Psychology Review, vol. 1, pp. 279-308, 1989.

[8] P. W. Foltz, W. Kintsch, and T. K. Landauer, "The measurement of textual coherence with Latent Semantic Analysis," Discourse Processes, vol. 25, pp. 285-307, 1998.

[9] B. Lemaire and P. Dessus, "A system to assess the semantic content of student essays," Journal of Educational Computing Research, vol. 24, pp. 305-320, 2001.

[10] E. Kintsch, D. Steinhart, G. Stahl, LSA Research Group, C. Matthews, and R. Lamb, "Developing summarization skills through the use of LSA-based feedback," Interactive Learning Environments, vol. 8, pp. 87-109, 2000.

[11] D. Wade-Stein and E. Kintsch, "Summary Street: Interactive Computer Support for Writing," Cognition and Instruction, vol. 22, pp. 333-362, 2004.

[12] V. Thibaudeau, "88 clefs pour identifier dans un texte un problème de logique ou d'expression de la pensée," Université de Laval, Laval 2000.

[13] R. Hübscher and S. Frizell, "Aligning theory and web-based instructional design practice with design patterns," in Proceedings of world conference on E-Learning in corporate government, healthcare, and higher education, G. Richards, Ed. Chesapeake: AACE, 2002, pp. 298-304. 